\title{
Role of the medulla oblongata in normal and high arterial blood pressure regulation: the contribution of Escola Paulista de Medicina - UNIFESP
}

\author{
SERGIO L. CRAVO ${ }^{1}$, RUY R. CAMPOS ${ }^{1}$, EDUARDO COLOMBARI ${ }^{1}$, \\ MÔNICA A. SATO ${ }^{2}$, CÁSSIA M. BERGAMASCHI ${ }^{3}$, GUSTAVO R. PEDRINO ${ }^{1}$, \\ MARCOS L. FERREIRA-NETO ${ }^{4}$ and OSWALDO U. LOPES ${ }^{1}$ \\ ${ }^{1}$ Departamento de Fisiologia, Universidade Federal de São Paulo, UNIFESP, Rua Botucatu, 862 \\ Vila Clementino, 04023-062 São Paulo, SP, Brasil \\ ${ }^{2}$ Departamento de Morfologia e Fisiologia, Faculdade de Medicina do ABC, Avenida Lauro Gomes, 2000 \\ Vila Sacadura, 09060-650 São Paulo, SP, Brasil \\ ${ }^{3}$ Departamento de Biociências, Universidade Federal de São Paulo, UNIFESP, Avenida Ana Costa, 95 \\ Vila Mathias, 11060-001 Santos, SP, Brasil \\ ${ }^{4}$ Faculdade de Educação Física, Universidade Federal de Uberlândia, UFU, Rua Benjamin Constant, 1286 \\ Bairro Aparecida, 38400-678 Uberlândia, MG, Brasil \\ Manuscript received on July 28, 2008; accepted for publication on May 13, 2009; \\ contributed by OSWALDO U. LOPES*
}

\begin{abstract}
Several forms of experimental evidence gathered in the last 37 years have unequivocally established that the medulla oblongata harbors the main neural circuits responsible for generating the vasomotor tone and regulating arterial blood pressure. Our current understanding of this circuitry derives mainly from the studies of Pedro Guertzenstein, a former student who became Professor of Physiology at UNIFESP later, and his colleagues. In this review, we have summarized the main findings as well as our collaboration to a further understanding of the ventrolateral medulla and the control of arterial blood pressure under normal and pathological conditions.
\end{abstract}

Key words: hypertension, baroreceptor reflexes, vasomotor nuclei, sympathetic nerve activity, arterial pressure.

\section{INTRODUCTION}

Several forms of experimental evidence gathered in the last 37 years have unequivocally established that the medulla oblongata harbors the main neural circuits responsible for the regulation of arterial blood pressure. Within this region, discrete groups of neurons act to generate and maintain the sympathetic vasomotor tone and arterial blood pressure. The medulla oblongata also contains the main site integrating signals arising from high- and low-pressure baroreceptors and chemorecep-

In commemoration of the $75^{\text {th }}$ anniversary of Escola Paulista de Medicina / Universidade Federal de São Paulo. *Member Academia Brasileira de Ciências Correspondence to: Dr. Sergio L. Cravo

E-mail: sldcravo@fcr.epm.br tors afferents. Dysfunctions of this circuitry are a common feature of many pathological conditions and may be the core of cardiovascular diseases including arterial hypertension.

Our current views of this circuitry derive mainly from evidence gathered in the last 35 years, especially those from the studies of Pedro Guertzenstein and his colleagues. The fact that Guertzenstein was a former medical student at UNIFESP who became Professor of the Department of Physiology later, and that many of us were able to contribute to the current view of cardiovascular regulation is a reason of pride and joy in the year in which UNIFESP commemorates its 75 years of foundation. 


\section{THE EARLY YEARS}

The quest for the localization of the area responsible for the maintenance of vasomotor tone remounts to the XIX century. However, almost a century elapsed between C. Dittmar's first attempts in Carl Ludwig's laboratories in Leipzig (1873) and the initial experiments performed by P. Guertzenstein in William Feldberg's laboratories in London (1971). Although Dittmar's experiments led him to the conclusion that there was a vasomotor center localized in the lower half segment of the medulla, that is the ventral portion, his observations did not allow him to differentiate between the tonic and the reflexogenic areas of the supposed center. Furthermore, his anatomical definition was still preliminary since it included a fairly large area. Based on the results obtained by Owsjannikow (1871) and Dittmar (1873) in cats, the vasomotor center could be located anywhere in an area of $4 \mathrm{~mm}$ of length along the cranio-caudal axis (starting at the obex) and comprehending another $4 \mathrm{~mm}$ of ventral tissue in the mediolateral plane.

Nearly one hundred years later, in March 1970, Pedro G. Guertzenstein, at that time a young scientist from Brazil, arrived in Feldberg's laboratories for a postdoctoral fellowship, staying there for three years. According to Feldberg's own words: "We, that is, Guertzenstein and myself, stumbled on the ventral surface of the brain as late as 1972. 'Our story' began with a simple experiment, with a fall in arterial blood pressure following the injection of a few milligrammes of pentobarbitone sodium (Nembutal) into a lateral cerebral ventricle." (Feldberg 1982).

During those three years, alone or in collaboration with many colleagues, Guertzenstein produced the impressive number of four communications to the Physiological Society (Guertzenstein, January 1971, Feldberg and Guertzenstein, January 1972, Guertzenstein, April 1972, Guertzenstein and Silver, June 1973) and five full papers published either in the Journal of Physiology or in the British Journal of Pharmacology (Feldberg and Guertzenstein 1972, Guertzenstein 1973, Bousquet and Guertzenstein 1973, Guertzenstein and Silver 1974, Edery and Guertzenstein 1974). Together with papers published much later after his return to Brazil, and including some developed during his last years at UNIFESP, these papers established the foundations of our current view of the ventrolateral medullary vasomotor nuclei and their role in the arterial blood pressure regulation. Since their publication, they were cited an average of 33 times/year, in a total amount of almost 1300 citations.

Out of these, the far most quoted and recognized as a classical paper is the one he published with the collaboration of Ann Silver (Guertzenstein and Silver 1974). In this paper they defined, for the very first time, the precise location of what is clearly recognized, until nowadays, as the rostroventrolateral medulla (RVLM), one and so far the most important source of tonic excitation to the sympathetic preganglionic neurons in the intermediolateral cell column of the spinal cord. Their results demonstrated unequivocally that, after a bilateral electrolytic destruction of a small area, not larger than $1 \mathrm{~mm}^{2}$ in the ventrolateral medulla, the blood pressure was no longer maintained and remained low for at least 6 hours. In Guertzenstein's own words: "Bilateral electrolytic destruction of the glycine sensitive area (GSA) produced a fall in arterial blood pressure to levels similar to those usually obtained in acute spinal animals, without signs of recovery for at least $6 \mathrm{~h}$, which was the longest period of time the animals were observed for." (Campos and Guertzenstein 1989).

The question about the role of the central nervous system in keeping arterial blood pressure levels was moved from where to how? The revolution in the way we thought about blood pressure regulation was shortly and precisely expressed by Feldberg (1982): "For a century the structures responsible for maintaining arterial blood pressure were thought to lie near the dorsal surface of the brain stem, on the floor of the fourth ventricle. Later, they were thought to be distributed more or less throughout the entire substance of the brain stem. Now we suggest that blood pressure may be maintained by the action of nerve cells located in a small bilateral region near its ventral surface".

Shortly after, in 1976, Feldberg and Guertzenstein published another fundamental paper showing the existence of a different area, caudal to the one already described, on which topic application of nicotine produced a marked fall in blood pressure due to the inhibition of the vasoconstrictor tone. Assuming that nicotine was acting as an excitatory drug, they proposed: "With the 
evidence so far available... there are at least two separate regions... a more rostral and a more caudal one", and also "Yet the action itself is probably an excitatory one exert on inhibitory neurons that form connexions with the vasomotor pathway". With these suggestions they had described what we would come to know as the caudal ventrolateral medulla (CVLM), and advanced the main properties of this region: its vasodepressor role through tonic and reflex inhibition of RVLM. A further characterization of this area in regulating cardiovascular functions, and particularly modulating cardiovascular reflexes, was developed after Guertzenestein's return to Brazil, and was pioneerly presented in a communication to the Physiological Society and published as a communication followed by a full paper (Guertzenstein and Lopes 1980, 1984). The route for the understanding of the CVLM and its implications on the regulation of sympathetic tone and on cardiovascular reflexes was fully open and ready to be understood.

Many years later, based on a rather puzzling set of experimental observations, Guertzenstein and Feldberg went on to propose the existence of a yet third vasomotor area in the ventrolateral medulla. Once more their vision was far ahead of their time. A further development in the characterization of the area they foresaw took another 10 years. This was also his final enterprise because of his premature death in 1994. However, in his last papers, he and his fellows in the Department of Physiology at UNIFESP were able to show that the third area, the caudal pressor area (CPA), contains cells with a tonic pressor activity that contributed to the maintenance of baseline levels of arterial pressure and furthermore, that the CPA-induced cardiovascular responses were mediated by CVLM, with the involvement of both glutamatergic and GABAergic synapses (Possas et al. 1994, Campos et al. 1994).

Figure 1 contains a schematic representation of our current view of the main vasomotor nuclei in the ventrolateral medulla as derived from the work of Guertzenstein and colleagues, and has been confirmed in literally thousands of papers published in the last 30 years. In this review, we summarized the main findings and our collaboration to the development in the knowledge of the ventrolateral medulla and the tonic and reflex regulation of the arterial blood pressure.

\section{THE ROSTRAL VENTROLATERAL MEDULLA AND THE GENERATION OF THE SYMPATHETIC VASOMOTOR TONE}

The early studies performed in cats by Guertzenstein and Feldberg were a landmark in our understanding of the mechanism by which the sympathetic vasomotor tone is generated by the central nervous system. There is now considerable evidence that a restricted group of specialized reticulospinal neurons located in the RVLM is crucial to maintain the sympathetic vasomotor tone in different species. The major characteristics of the RVLM neurons include: direct monosynaptic excitatory connections to identified pre-ganglionic sympathetic neurons of the spinal cord, tonic activity and baroceptor sensitivity.

The RVLM receives inputs from a number of different nuclei in the brain and also sends projections to many other regions involved in the cardiovascular, respiratory and hormonal control. A number of reciprocal innervations between the RVLM and other brain nuclei strongly suggest that the RVLM is not only an important region involved in the maintenance of the tonic sympathetic vasomotor tone. It might also be an integrative center controlling the cardiovascular functions, processing the information from the peripheral nerves (baroreceptor and chemoreceptor reflexes) and from other nuclei acting as a key region to maintain cardiovascular homeostasis.

The RVLM neurons have been extensively studied using different approaches. First, they were identified by topical application of drugs (glycine or GABA) in the ventral surface of the brainstem by Guertzenstein and colleagues. When applied to the rostral part of the ventrolateral medulla in cats, such amino acids caused a large fall in blood pressure and cardiac output in the region denominated as the glycine sensitive area, now denominated the RVLM (Guertzenstein and Silver 1974, Campos and Guertzenstein 1989). Subsequently, the anatomical location of the RVLM was defined in the rat and in the rabbit using microinjections of amino acids directly into the ventrolateral medulla parenchyma (Ross et al. 1984). A more precise localization of the RVLM neurons was achieved, the cardiovascular neurons were then localized ventrally to the rostral part of the nucleus ambiguous (Dampney 1994). The precise location of the RVLM region allowed the study of these neurons with more refined and improved techniques including single 


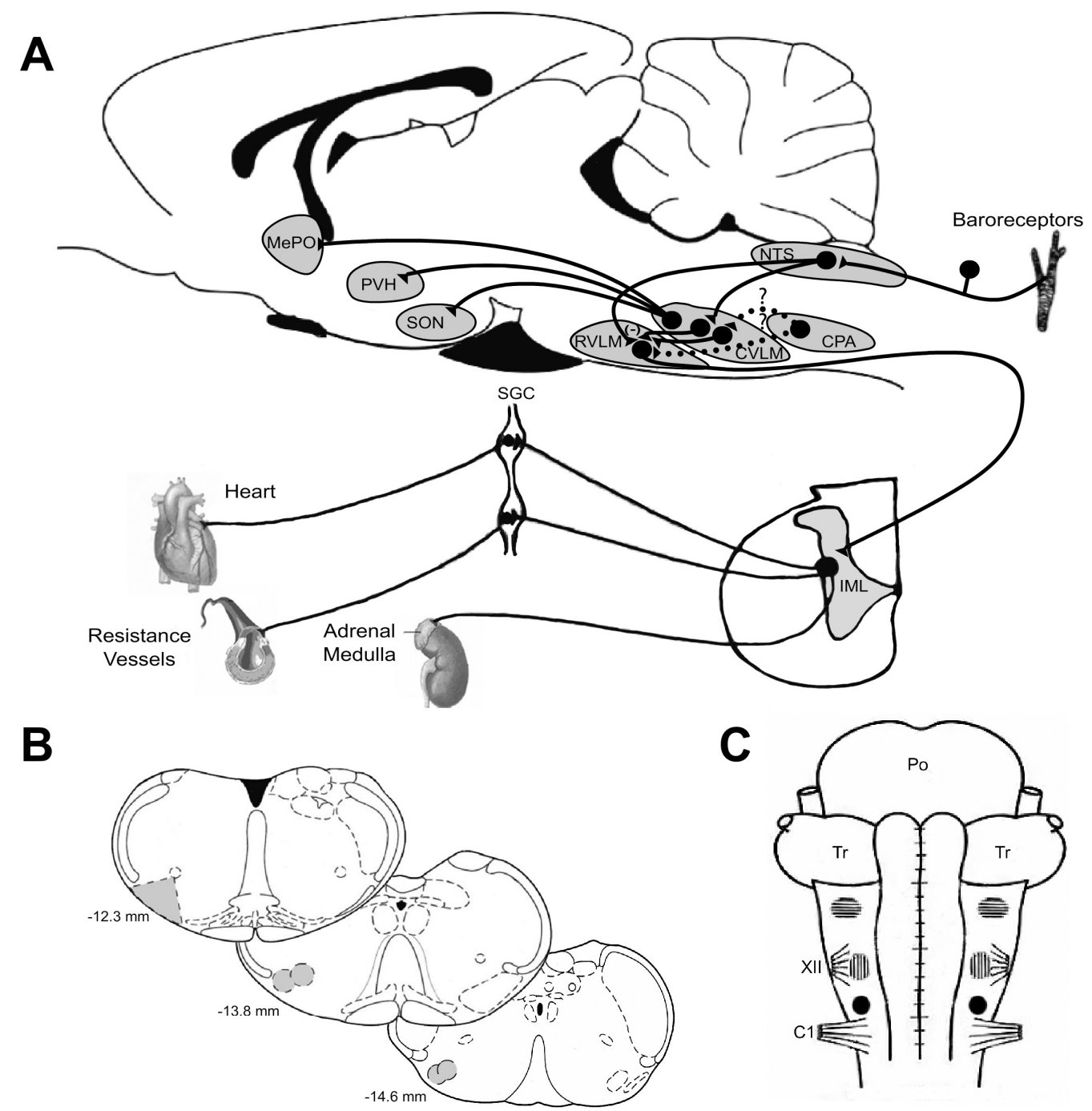

Fig. 1 - A: The current view of the role of the ventrolateral medulla and cardiovascular regulation: tonic sympathetic activity to the heart, resistance vessels and adrenal medulla derive from preganglionic sympathetic neurons (SPNs) located in the intermediolateral cell column. SPNs are tonically excited by direct bulbospinal neurons located in the rostral ventrolateral medulla (RVLM). Activity of RVLM neurons is regulated by inhibitory afferents located in the caudal ventrolateral medulla (CVLM) and by activity of neurons in caudal pressor area (CPA). The nucleus tractus solitarius (NTS) is the primary site receiving afferents from high and low pressure baroceptors and chemoreceptors. From the NTS this information is transferred to the VLM. Arterial baroreceptors reflexes are mediated by the inhibitory CVLM-RVLM pathway. From CVL ascending efferents project to several nuclei involved in water and salt intake and cardiovascular control, e.g., the Median Preoptic Nucleus (MePO), the paraventricular nucleus of hypothalamus (PVH) and the supraoptic nucleus (SON). B: Schematic representation of three coronal sections of the rat medulla oblongata at the levels of the RVLM, CVLM and CPA, respectively. The hatched areas represent the areas from which characteristic cardiovascular responses can be evoked. C: Diagram representing the rat's ventral medullary surface showing the localizations (from rostral to caudal) of the RVLM, CVLM and caudal pressor area (CPA) (Modified from Cravo et al. 2006).

unit electrophysiology, immunohistochemistry and cellular molecular biology techniques.

The RVLM neurons have been studied using extracellular recording (Brown and Guyenet 1984, 1985, Morrison et al. 1988, Campos and McAllen 1999) and intracellular recordings (Lipski et al. 1996). However, despite the large number of studies on the RVLM and its recognized importance on the sympathetic vasomotor tone generation, the basis for the tonic ongoing activity of these neurons is not yet fully understood. 
At least, under specific experimental conditions in vivo, fast excitatory synaptic inputs (EPSPs) appear to drive the RVLM spiking activity. The ongoing activity of these neurons resulted of synaptic inputs, with individual action potentials usually preceded by identifiable fast EPSPs (Lipski et al. 1996). These findings are in agreement with the network hypothesis of the generation of sympathetic vasomotor tone proposed by Barman and Gebber (1987). The hypothesis implies that the activity of premotor neurons in vivo is dependent on excitatory inputs from other brainstem nuclei. The question is: where are the sources of the synaptic drive to the RVLM?

There is a large body of evidence showing a number of nuclei in the brain and peripheral nerves from which synaptic excitation of RVLM neurons can be achieved, following electrical or chemical stimulation (Sun and Guyenet 1986, Cechetto and Chen 1992). Although a number of brain stem regions, when activated, cause sympathetic activation via the RVLM, few regions may provide a tonic excitatory drive to the RVLM neurons to support their activity. So far, some regions in the brain stem have been identified that may provide a tonic drive to the RVLM presympathetic neurons. Among these regions are:

1) the lateral tegmental field (LTF) in the dorsal formation of the medulla oblongata (Barman and Gebber 1987),

2) the pontine reticular formation (Hayes and Weaver 1992) and,

3) the caudal pressor area (CPA) in the caudal end of the ventrolateral medulla (Campos and McAllen 1999).

The LTF has a sympathetic-related activity and contains neurons that respond to the baroreceptor reflex, with an increase or a decrease in their activity in response to baroreceptor activation. The barosensitive LTF neurons send projections to the RVLM and are probably one source of excitatory inputs to the region. Furthermore, blockade of $N$-methyl-D-aspartate (NMDA) receptors in the LTF abolished baroreceptor reflex control of sympathetic activity (Barman and Gebber 1987). In a recent study in cats, the same group showed that a blockade of non-NMDA receptors in the LTF signifi- cantly attenuated the reflex increase in cardiac and vertebral sympathetic nerve activity in response to electrical stimulation of vagal afferents or by activation of arterial chemo receptors (Orer et al. 2004). On the other hand, the reflex sympathetic activation, in response to electrical stimulation of the sciatic or trigeminal nerve, was not affected by previous glutamatergic blockade within the LTF. These data suggest an important and specific role of the LTF controlling the sympathetic reflex pathways. However, the role of this region in supporting the vasomotor tone needs to be clarified. Hitherto the evidence that blood pressure falls when the LTF cell bodies are inactivated is lacking. Furthermore, the anatomical localization and the role of LTF neurons in rats are not very well defined, and the possibility that there is some homology between the LTF in the cat and the CVLM in rats cannot be ruled out and needs to be clarified.

A second region that can support the RVLM ongoing activity is the pontine reticular formation. Hayes and Weaver (1992) found that glycine microinjection into a diffuse region of the pontine reticular formation caused a decrease in blood pressure in anesthetized rats. However, the full meaning of this interaction with the vasomotor tone needs to be more thoroughly studied.

Finally, the CPA is probably an important source to maintain the RVLM activity. The CPA was discovered in cats by Feldberg and Guertzenstein (1986) and in rats by Gordon and McCann (1988). In anesthetized rats, bilateral inhibition of the CPA by GABA or glycine decreased the blood pressure by $30-40 \mathrm{mmHg}$ (Campos et al. 1994). In rabbits, CPA inhibition caused a similar decrease in the arterial pressure and almost abolished the renal sympathetic nerve activity (Dampney et al. 2003). The decrease in the arterial pressure is probably mediated by a decrease in RVLM activity. It was shown that the RVLM sympathetic premotor neurons were inhibited on an average of $40 \%$ during a unilateral or bilateral microinjection of glycine into the CPA (Campos and McAllen 1999). Taken together, these data suggest that an important fraction of resting activity of sympathetic premotor neurons of the RVLM depends on a synaptic drive from the CPA. However, the exact physiological role of the CPA is not yet known. Furthermore, there is no information on what drives the CPA neurons and what kind of neurons exists within this region. 
Concluding, despite the large number of studies, understanding how RVLM neurons work to maintain the sympathetic vasomotor drive in non-anesthetized animals remains a challenge, and the characteristics of depolarization and the membrane properties of the RVLM neurons in intact and conscious animals are not fully understood.

There are two major indications that the RVLM is involved in the long-term control of sympathetic activity and blood pressure:

1) pharmacological evidence indicates that the RVLM is the major site of action of centrally antihypertensive agents such as clonidine and moxonidine (Ernsberger et al. 1987), and

2) experimental fulminating neurogenic hypertension induced through lesion of the CNS at sites such as the nucleus of the solitary tract or the caudal ventrolateral medulla occurred as a consequence of RVLM disinhibition (Doba and Reis 1973, Blessing and Reis 1982). Recently, this hypothesis was supported by a new evidence showing that changes in neurotransmission within the RVLM are related to acute or chronic hypertension.

Electrophysiological studies in spontaneously hypertensive rats (SHRs) have confirmed increases in the firing rates of RVLM barosensitive neurons containing excitatory amino acids and terminating in the intermediolateral cell column of the spinal cord, where the preganglionic sympathetic neurons SPNs are located (Chalmers et al. 1992, Chan et al. 1991). We can hypothesize that an increase in excitatory neurotransmission in the RVLM, glutamatergic activity in particular, is in part responsible for the sympathetic activation seen in experimental hypertension.

In an experimental model of renovascular (twokidney, one-clip Goldblatt) hypertension in rats, bilateral blockade of RVLM glutamatergic synapses by microinjection of kynurenic acid, a broad-spectrum glutamate receptor antagonist, decreased blood pressure to a degree similar to that caused by ganglionic blockade. In addition, the blockade of excitatory amino acid input to the RVLM did not alter the blood pressure in normal animals (Bergamaschi et al. 1995). These findings suggest that, in the RVLM, glutamate plays a tonic role in renovascular hypertensive animals, but not in normotensive animals. Figure 2 shows a representative recording of blood pressure and renal sympathetic activity during glutamatergic synapses blockade into the RVLM of a renovascular hypertensive rat.

The mechanisms by which glutamate is activated in the RVLM during renovascular hypertension are not fully understood. One possibility is that a high level of circulating angiotensin II (Ang II) excites RVLM neurons directly or indirectly, causing sympathoexcitation. It has been documented that direct injection of Ang II into the RVLM caused blood pressure to increase in anesthetized animals (Allen et al. 1988, Andreatta et al. 1988, Sakai and Dampney 1990). In addition, introduction of an Ang II antagonist into the RVLM has been shown to produce significant drops in the blood pressure and sympathetic activity (Sakai and Dampney 1990, Averill et al. 1994, Ito and Sved 1996). These findings suggest that endogenous Ang II causes tonic excitation of RVLM neurons, and this may be relevant to sympathetic activation in hypertension.

In renovascular hypertensive rats, as well as in SHRs (Ito et al. 2000), Dahl salt-sensitive rats (Ito et al. 2001) and rats used in an experimental model of pulsatile compression of the RVLM (Morimoto et al. 1999), the blockade of excitatory amino acid receptors in the RVLM elicited profound decreases in the arterial pressure. Our hypothesis is that the increased glutamatergic activity in the RVLM seen in hypertension is in part mediated by local or circulating Ang II.

This hypothesis is supported by studies in renovascular hypertensive rats, in which the depressor effect of glutamate blockade in the RVLM was not observed in animals pretreated with a low dose of an Ang II enzyme converter inhibitor (captopril), suggesting that the glutamatergic activation of the RVLM in this model depended on high levels of circulating Ang II (Carvalho et al. 2003).

Other evidence supporting an increase of glutamatergic inputs to the RVLM, in response to Ang II, has been provided by studies using microdialysis, in which intravenous infusion of Ang II at a very low rate over a period of several hours caused a significant increase in glutamate release in the RVLM (Katahira et al. 1994, Moriguchi et al. 1994). In addition, intravenous admin- 


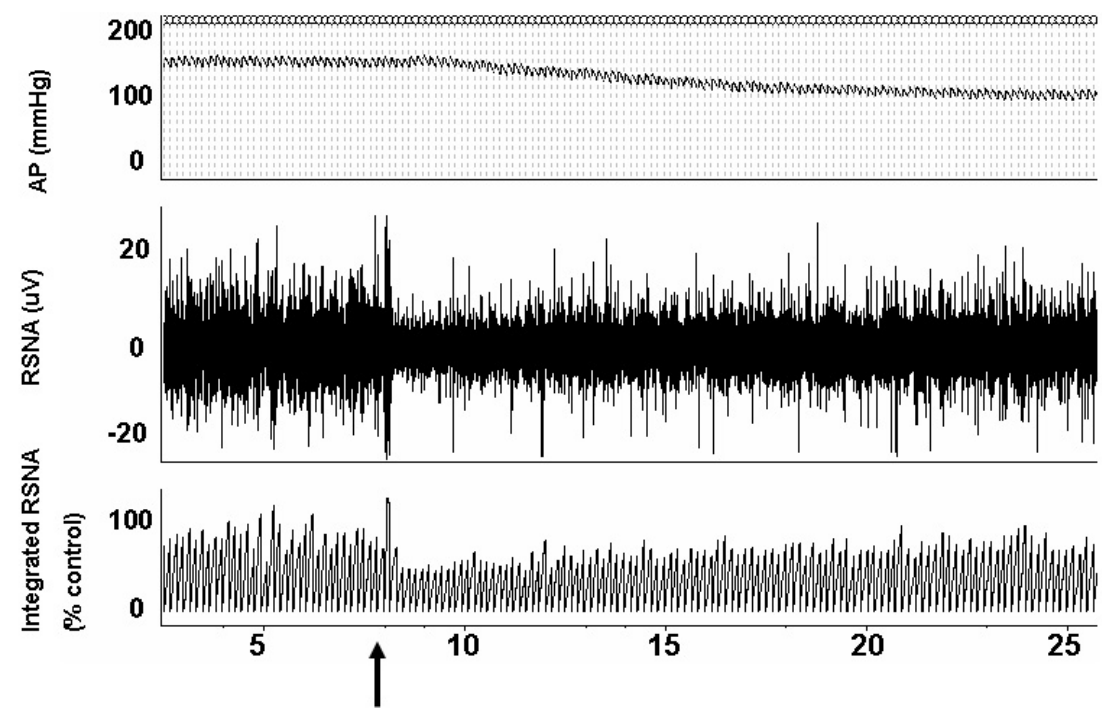

Fig. 2 - Segments of original recording demonstrating arterial pressure (AP), renal sympathetic nerve activity (RSNA) and integrated RSNA responses to bilateral microinjection of kynurenic acid ( $4 \mathrm{nmol} / 100 \mathrm{nl}$, bilaterally) into the RVLM (arrow) in a renovascular hypertensive rat (Goldblatt model, 2 kidneys-1clip). Time in seconds. (Modified from Bergamaschi et al. 1995).

istration of an angiotensin-converting enzyme inhibitor caused a decrease in glutamate release in the RVLM (Katahira et al. 1994, Moriguchi et al. 1994). All these data support the idea that there is an interaction between circulating Ang II and glutamatergic drive to the RVLM. However, the cellular mechanisms by which Ang II causes an increase in glutamatergic actions in the RVLM have yet to be clarified.

Since circulating Ang II does not have direct access to the RVLM, the excitatory effect of Ang II is likely to be derived from angiotensinergic neural inputs or from paracrine secretion within the ventrolateral medulla (Van et al. 1980, Fink 1997). Central $\mathrm{AT}_{1}$ receptor-mediated Ang II activity is mediated by facilitation of excitatory transmission, not only via glutamate but also via catecholamine release (Ferguson et al. 2001), substance $P$ (Paton et al. 2001) and, paradoxically, enhanced inhibitory GABAergic neurotransmission (Paton and Kasparovo 1999).

A model postulated to explain the sympathoexcitation that Ang II causes via the RVLM was proposed years ago by Joy and Lowe (1970). According to their hypothesis, the area postrema (AP) is an important locus at which circulating Ang II modulates the sympathetic vasomotor tone originating in the ventrolateral medulla. Ablation of the AP significantly inhibited the increase in the blood pressure associated with chronic intravenous infusion of Ang II in rats (Fink et al. 1987). A direct or indirect neural pathway from the AP to the RVLM might be involved in the increased excitatory neurotransmission mediated by circulating Ang II. In addition, local paracrine secretion of Ang II in the ventrolateral medulla may participate in this mechanism.

It is interesting that, in other models of sympathetic activation such as acute or chronic water deprivation, there is an increase in excitatory amino acid drive in the RVLM that is caused specifically by an increased osmolarity rather than by a decreased blood volume (Brooks et al. 2004).

We can speculate that the sympathoexcitation may be in part a consequence of an increase in the glutamatergic actions within the RVLM, not only in experimental models of hypertension, but also under other conditions associated with increased sympathetic drive. As proposed by Lipski (Lipski et al. 1996), it is possible that, under normal conditions, RVLM premotor neuron activity is determined by the balance between excitatory and inhibitory synaptic inputs, including amino acid excita- 
tory mechanisms. However, under special conditions, such as hypertension, an imbalance between these inputs, resulting in an increased excitatory activity within the RVLM, may enhance the tonic activity of RVLM neurons.

\section{THE CAUDAL VENTROLATERAL MEDULLA (CVLM)}

The term caudal ventrolateral medulla (CVLM) was initially proposed by Reis and coworkers (Ross et al. 1984) and defined essentially in analogy with the rostral ventrolateral medulla. The CVLM, as functionally defined in the rat, is certainly the equivalent of the nicotine area described by Feldberg and Guertzentein in cats (Feldberg and Guertzensteim 1976). However, while the RVLM can be functionally and anatomically defined in a rather discrete area, the CVLM is a much larger area whose boundaries are not yet precisely established. In the rat, CVLM neurons are spread in the rostrocaudal axis from the vicinity of the RVLM to the spinal-medullary junction (Ross et al. 1985, Ruggiero et al. 1994). The CVLM is also a functionally heterogeneous area. It contains at least two separate systems that are distinct in their connections and function. These circuits are involved in the control of peripheral resistance and the volume and composition of the extracellular compartment.

The CVLM circuitry for controlling peripheral resistance is represented by a group of sympatoinhibitory neurons scattered around the periambigual area whose function is essential in cardiovascular regulation. CVLM stimulation produces marked hypotension and bradicardia due to a reduction in the sympathetic vasoconstrictor drive (Blessing and Reis 1982, Cravo et al. 1991). Anatomical and functional evidence indicate that CVLM sympathoinhibition is mediated trough the inhibition of RVLM neurons (Granata et al. 1986, Willete et al. 1987). Retrograde tracing studies demonstrated that CVLM neurons do not contact SPNs in the intermediolateral cell column, but sent dense projections to the RVLM (Ross et al. 1985). There, putative GABAergic CVLM neurons form inhibitory synapses with bulbospinal RVLM neurons (Aicher et al. 1996), providing a tonic GABAergic inhibition. When the CVLM is lesioned or functionally inactivated, there are marked increases in sympathetic nerve activity and neurogenic hypertension (Blessing et al. 1982, Cravo et al. 1991).
This hypertension can reach levels capable of producing ventricular failure and death due to acute ventricular failure and pulmonary edema.

Tracing studies also indicate that the CVLM receives numerous projections from the NTS areas receiving primary baroreceptor afferent fibers (Ross et al. 1985). It is now accepted that the CVLM contains an essential interneuron of the baroreceptor reflex arch. Inactivation of the CVLM abolished baroreceptor adjustments (Cravo et al. 1991, Granata et al. 1986). Extracellular recordings have identified within the CVLM neurons with all characteristics of a baroreceptor interneuron: orthodromical activation by electrical stimulation of baroreceptor afferents, NTS stimulation or increases in the arterial blood pressure and direct projections to RVLM (Jeske et al. 1993). From the work of Feldberg, Guertzenstein and Lopes, our recognition of the CVLM reflex and tonic sympathoinhibition has come a long way. However, a key aspect of CVLM functions remains largely unknown: similarly to the rostral medulla, neurons of the CVLM exhibit tonic activity which is under a tonic GABAergic inhibitory control. The origins of both the tonic activity and the GABAergic afferents are unidentified. Results obtained with selective microinjection of glutamatergic and GABAergic antagonists suggested that CVLM tonic activity is maintained through a combination of tonic excitatory and inhibitory afferents whose source, however, remains largely unknown (Guyenet et al. 1987, Campos Jr. et al. 1994).

Besides its role in the peripheral resistance regulation, the CVLM neurons are also important for body fluid homeostasis. In the beginning of the 1960s, Dahlström and Fuxe (1964) showed the presence of catecholaminergic neurons in this area (A1 noradrenergic neurons). Initially it was thought that A1 neurons were part of the CVLM sympathoinhibitory group (Granata et al. 1986), but later it became clear that these cells were GABAergic and located medially to the A1 neurons. Now it is well accepted that A1 neurons are central elements in regulating the volume and composition of the extracellular compartment (Pedrino et al. 2008, 2006, Howe et al. 2004, Buller et al. 1999, Hochstenbach and Ciriello 1995, Smith et al. 1995, Head et al. 1987).

Neuroanatomical studies have shown that A1 noradrenergic neurons receive projections from arterial baro- 
receptors as well as from vagal cardiopulmonary volume receptors ( $\mathrm{Li}$ et al. 1992, Day et al. 1992, Day and Sibbald 1990). These neurons also are reciprocally connected with hypothalamic regions known for their involvement in neuroendocrine, hydroelectrolytic, and cardiovascular regulation, including the median preoptic nucleus (MnPO), the subfornical organ (SFO), the paraventricular nucleus (PVN), and the supraoptic nucleus (SON, Tanaka et al. 1997, Tucker et al. 1987, Saper et al. 1983).

Results obtained in studies developed in the last 10 years in our group demonstrated that A1 neurons are part of central pathways involved in cardiovascular responses induced by acute changes of volume and composition of the extracellular compartment. In intact anesthetized rats, isotonic volume expansion or hypernatremia induced a sustained renal vasodilation. The observed renal vasodilation is due to a reduction of the renal sympathetic nerve activity and the release of vasoactive peptides. Dennervation of the baroreceptors or electrolytic lesions of the anterioventral wall of the third ventricle of the brain (AV3V) abolished renal vasodilatation induced by volume expansion or hypernatremia (Pedrino et al. 2005, Colombari et al. 2000, Colombari and Cravo 1999). Blockade of the adrenergic transmission in the AV3V reduced ANP release and renal vasodilation induced by changes in circulating volume (Antunes-Rodrigues et al. 1993, Pedrino and Cravo 2006 Abstract). Taken together, these findings suggest that the catecholaminergic innervations, originating mainly from A1 neurons, represent a necessary neural pathway involved in responses to acute changes in the volume or composition of the extracellular compartment.

A functional relationship between A1 neurons and cardiovascular and humoral responses to acute reductions in central blood volume was demonstrated in previous studies (Buller et al. 1999, Smith et al. 1995, Head et al. 1987). Buller et al. (1999) demonstrated that the lesion of the region where A1 noradrenergic neurons are located reduced the number of Fos-positive neurosecretory vasopressin cells in the SON and PVN induced by hypotensive hemorrhage. Similarly, other studies demonstrated that lesions of these neurons reduced the vasopressin secretion induced by a decreased circulating volume (Smith et al. 1995, Head et al. 1987).
Despite the abundance of evidence provided by studies to support this important role of A1 noradrenergic neurons in acute reductions of blood volume, little is known regarding the role of these neurons during hypernatremia or volume expansion. Previous studies employing early gene expression have demonstrated that subcutaneous, intraperitoneal or intravenous administration of hypertonic saline or isotonic volume expansion increases Fos and c-Fos mRNA expression in the A1 noradrenergic neurons (Howe et al. 2004, Hochstenbach and Ciriello 1995). Moreover, in recent studies, we demonstrated that renal vasodilation and sympathoinhibition induced by increases in plasma sodium concentration was blunted in animals submitted to specific lesion of A1 noradrenergic neurons (Pedrino et al. 2006). These studies are the initial observations that A1 noradrenergic neurons are involved on sympathetic and cardiovascular changes induced by hypernatremia.

Overall, these recent evidence support the idea that A1 neurons in the CVLM are activated upon stimulation of peripheral baroreceptor and cardiopulmonary afferents, engaging efferent pathways to AV3V and PVN that regulate the endocrine and autonomic responses relevant to body fluid homeostasis and cardiovascular regulation. Since A1 neurons are important to sympathetic and peripheral resistance response to changes of circulating volume, the irregular function of these neurons results in an inefficient control of the renal sympathetic activity which could contribute to the pathophysiology of hypertension, congestive heart failure and cirrhosis.

\section{THE NUCLEUS OF THE SOLITARY TRACT (NTS): OLD AND NEW PATHWAYS TOWARD THE VENTRAL SURFACE OF THE MEDULLA}

Different evidence has shown that the NTS constitutes the primary site of integration of different viscerosensory afferents. The intermediate and commissural portions of the NTS are mostly known as the "cardiovascular NTS". The intermediate NTS receives mainly carotid and aortic baroreceptor afferents, while the commissural NTS is the site of termination of arterial chemoreceptors and also aortic baroreceptor fibers (Cottle 1964, Crill and Reis 1980, Miura and Reis 1969, 1972, Spyer 1981, Finley and Katz 1992, Ciriello et al. 1994, Colombari et al. 1996). Information arriving from these afferents 
into the NTS, which in turn sends efferent projections to different areas involved in cardiovascular regulation. The ventrolateral medullary surface is a main site of these efferents.

Studies have shown that NTS efferent terminals synapse onto neurons in the CVLM that project to the RVLM (Aicher et al. 1996). Although neuroanatomical and functional evidence suggest that the information of arterial baroreceptors are integrated in the classic circuit NTS-CVLM-RVLM, different findings (Willete et al. 1984a, b) have shown that the stimulation of the aortic depressor nerve elicited a pressor response in rats with inhibition of CVLM neurons. Indeed, this apparently paradox effect that differs from the expected hypotension and bradycardia evoked by the aortic baroreceptor stimulation suggested that the pressor response would be dependent on a direct pathway from NTS to the RVLM. Urbanski and Sapru (1988a, b) have shown that a microinjection of L-glutamate into the NTS in anesthetized rats that had the ipsilateral CVLM inhibited with muscimol or lidocaine produced a pressor response. This effect was the opposite from the expected response in anesthetized rats with an intact CVLM. Immunohistochemical studies showed the existence of projections from the NTS to the RVLM (Ross et al. 1985). In a different approach, NTS glutamatergic stimulation in a non-anesthetized condition consistently produced increases in arterial pressure. However, in commissural NTS-lesioned rats, such pressure response was turn in a fall in arterial pressure as demonstrated in anesthetized animals (Colombari et al. 1996). Taken together, these data support two hypotheses: a) in addition to the sympatoinhibitory projections from NTS to the ventral surface, the NTS drives sympathoexcitatory pathways as well; b) this sympatoexcitatory responses could be integrated via a direct NTS-RVLM pathway.

Further studies have shown that the pressor responses induced by stimulation of arterial chemoreceptors with $\mathrm{N}_{2}$ were not affected by CVLM inhibition neurons or the blockade of glutamatergic transmission in the CVLM (Koshiya et al. 1993). Nevertheless, glutamatergic blockade in the RVLM abolished these pressor responses. These results suggest that the sympathoexcitatory component of the chemoreceptor reflex response depends on a possible direct glutamatergic pathway from the NTS to the RVLM (Koshiya et al. 1993). Electrophysiological evidence has also shown that chemosensitive neurons in the commissural subnucleus of the NTS are antidromically activated by the RVLM, which suggested that commissural NTS neurons arborize in the RVL (Koshiya and Guyenet 1996). These findings support the idea that not only the intermediate but also the commissural subnucleus of the NTS would project directly to the RVLM.

Although the commissural subnucleus of the NTS is specially known for integrating the chemoreceptor afferent information, it has been shown that lesions of this subnucleus of the NTS abolished the hypertensive response evoked by the aortic baroreceptor denervation (Sato et al. 1999). Electrolytic lesions of the commissural NTS also elicited a marked fall in arterial pressure in spontaneously hypertensive rats (SHR), but not in normotensive Wistar-Kyoto rats (Sato et al. 2001). These lesions abolished the pressor response of the chemoreceptor reflex and attenuated the sympathoexcitatory component of the baroreceptor reflex in SHR (Sato et al. 2001, Colombari et al. 2001). Inhibitions of the commissural NTS neurons have also reduced the splanchnic sympathetic nerve activity and, consequently, the arterial pressure in SHR, but not in normotensive rats (Sato et al. 2002). Indeed, the integrity of the commissural NTS seems to be essential for the development of the hypertensive response in aortic denervated rats or for the maintenance of the high blood pressure in SHR, which suggest a possible tonic activity of these neurons for the hypertensive condition. In addition, the microinjection of substance $\mathrm{P}$ into the commissural NTS of juvenile SHR reduced the thoracic sympathetic trunk nerve activity and induced vasodilatation, but not in normotensive WKY rats. Hence, a possible neurotransmitter which might be up-regulated in this hypertension model would be the substance P (AP Abdala et al., unpublished data). Other studies have shown that the blockade of excitatory amino acid receptors in the RVLM reduced arterial pressure in SHR with little effect in normotensive rats (Ito and Sved 1997). Taken together, these evidences suggest that the commissural NTS is likely to be an important source of excitation to RVLM neurons and, therefore, may constitute a neural pathway which can be altered and possibly tonical- 
ly active under pathophysiological conditions such as hypertension.

Although either the intermediate or the commissural NTS have been shown as a possible source for a direct excitation of the RVLM, whereas the CVLM has been known as a source of RVLM inhibition, new findings suggest changes in this view of the brain stem network. Moreira et al. (2005) showed that the blockade of the glutamatergic receptors in the NTS or the inhibition of the CVLM increased arterial pressure and heart rate as previously demonstrated (Guyenet et al. 1987, Willette et al. 1987, Dampney 1994, Ito and Sved 1997). However, a new finding of this study was the demonstrations that, after the simultaneous blockade of the glutamatergic receptors of the NTS and the inhibition of the CVLM, blood pressure and mesenteric and hindquarter vascular resistances were reduced below baseline levels. These findings suggest the existence of an important pressor mechanism arising from the NTS, and also that an excitatory pathway from the CVLM to the RVLM is likely to be involved in the control of vascular resistance and arterial pressure.

\section{CONCLUDING REMARKS}

The work of Guertzenstein and colleagues has defined what today we recognize as the main circuitry in the generation of the vasomotor sympathetic activity and blood pressure regulation. His pioneering work endowed our comprehension of blood pressure regulation. Several main questions remain open and we hope to continue contributing to their answers. This review is dedicated to him, a distinguished scientist and a dearly missed friend.

\section{ACKNOWLEDGMENTS}

The authors gratefully acknowledge the support of Fundação de Amparo à Pesquisa do Estado de São Paulo (FAPESP), Conselho Nacional de Desenvolvimento e Tecnologia (CNPq) e Coordenação de Aperfeiçoamento de Pessoal de Nível Superior (CAPES).

\section{RESUMO}

Numerosas formas de evidência experimental obtidas nos últimos 37 anos demonstraram inequivocamente que a medula oblongata contém os principais circuitos responsáveis pela geração e manutenção do tono vasomotor e a regulação da pressão arterial. A visão atual que possuímos destes circuitos deriva em grande parte dos estudos de Pedro Guertzenstein, um estudante e mais tarde Professor de Fisiologia da UNIFESP e seus colaboradores. Nesta revisão nós sumarizamos os seus principais resultados assim como a nossa colaboração para uma melhor compreensão da regulação da pressão arterial em condições normais e patológicas.

Palavras-chave: hipertensão, reflexos baroceptores, núcleos vasomotores, atividade simpática, pressão arterial.

\section{REFERENCES}

Aicher SA, Saravay RH, Cravo S, Jeske I, Morrison SF, ReIs DJ AND Milner TA. 1996. Monosynaptic projections from the nucleus tractus solitarii to $\mathrm{C} 1$ adrenergic neurons in the rostral ventrolateral medulla: comparison with input from the caudal ventrolateral medulla. J Comp Neurol 373: 62-75.

Allen AM, DAmpney RA And Mendelsohn FA. 1988. Angiotensin receptor binding and pressor effects in cat subretrofacial nucleus. Am J Physiol Heart Circ Physiol 255: H1011-1017.

Andreatta SH, Averill DB, Santos RAS And FerRARIO CM. 1988. The ventrolateral medulla: A new site of the action of the renin-angiotensin system. Hypertension 11: I163-166.

Antunes-Rodrigues J, Marubayashi U, FaVAretto AL, GutKowska J And McCAnn SM. 1993. Essential role of hypothalamic muscarinic and alpha-adrenergic receptors in atrial natriuretic peptide release induced by blood volume expansion. Proc Natl Acad Sci USA 90: 10240-10244.

AVerill DB, Tsuchihashi T, Khosla C ANd Ferrario CM. 1994. Losartan, nonpeptide angiotensin II type 1 (AT1) receptor antagonist, attenuates pressor and sympathoexcitatory responses evoked by angiotensin II and Lglutamate in rostral ventrolateral medulla. Brain Res 665 : 245-252.

BARMAN SM AND GeBber GL. 1987. Lateral tegmental field neurons of cat medulla: a source of basal activity of ventrolateral medullospinal sympathoexcitatory neurons. J Neurophysiol 57: 1410-1424.

Bergamaschi CT, CAmpos RR, Schor N AND Lopes OU. 1995. Role of the rostral ventrolateral medulla in maintenance of blood pressure in rats with Goldblatt hypertension. Hypertension 26: 1117-1120. 
BLESSING WW AND REIS DJ. 1982. Inhibitory cardiovascular function of neurons in the caudal ventrolateral medulla of the rabbit: relationship to the area containing A1 noradrenergic cells. Brain Res 253: 161-171.

Blessing WW, JAeger CB, Ruggiero DA And Reis DJ. 1982. Hypothalamic projections of medullary catecholamine neurons in the rabbit: a combined catecholamine fluorescence and HRP transport study. Brain Res Bull 9: 279-286.

Bousquet P AND GUERTZENSTEIN PG. 1973. Localization of the central cardiovascular action of clonidine. Brit $\mathrm{J}$ Pharmac 49: 573-579.

Brooks VL, Freeman KL and ODonaughy TL. 2004. Acute and chronic increases in osmolality increase excitatory amino acid drive of the rostral ventrolateral medulla in rats. Am J Physiol Regul Integr Comp Physiol 287: R1359-1368.

Brown DL AND Guyenet PG. 1984. Cardiovascular neurons of brain stem with projections to spinal cord. Am J Physiol 247(6 Pt 2): R1009-1016.

BROWn DL AND GUYENET PG. 1985. Electrophysiological study of cardiovascular neurons in the rostral ventrolateral medulla in rats. Circ Res 56: 359-369.

Buller KM, SMith DW AND DAY TA. 1999. Differential recruitment of hypothalamic neuroendocrine and ventrolateral medulla catecholamine cells by non-hypotensive and hypotensive hemorrhages. Brain Res 834: 42-54.

Campos RR and Guertzenstein PG. 1989. Role of the glycine sensitive area in the regulation of cardiac output. Prog Brain Res 81: 243-251.

CAMPos RR And MCALLEn RM. 1999. Cardiac inotropic, chronotropic, and dromotropic actions of subretrofacial neurons of cat RVLM. Am J Physiol Reg Integr Comp Physiol 45: R1102-1111.

CAmpos Jr RR, Possas OS, CRavo SL and Lopes OU AND Guertzentein PG. 1994. Putative pathways involved in cardiovascular responses evoked from the caudal pressor area. Braz J Med Biol Res 27: 2467-2479.

Carvalho TH, Bergamaschi CT, Lopes OU AND CAMPOS RR. 2003. Role of endogenous angiotensin II on glutamatergic actions in the rostral ventrolateral medulla in Goldblatt hypertensive rats. Hypertension 42: 707-712.

Cechetto DF And Chen SJ. 1992. Hypothalamic and cortical sympathetic responses relay in the medulla of the rat. Am J Physiol 263(3 Pt 2): R544-552.

Chalmers J, Arnolda L, Kapoor V, LlewellynSmith I, Minson J And Pilowsky P. 1992. Amino acid neurotransmitters in the central control of blood pressure and in experimental hypertension. J Hypertens 10(Suppl): S27-37.

Chan R, Chan Y And Won T. 1991. Electrophysiological properties of neurons in the rostral ventrolateral medulla of normotensive and spontaneously hypertensive rats. Brain Res 549: 118-126.

Ciriello J, Hochstenbach, SL and Roder S. 1994. Central projections of baroreceptor and chemoreceptor afferent fibers in the rat. In: ROBIN I, BARROCO A AND BOCA RATON FL (Eds), Nucleus of the solitary tract. CRC Press, Inc p. 35-50.

Colombari DS AND CRAVO SL. 1999. Effects of acute AV3V lesions on renal and hindlimb vasodilation induced by volume expansion. Hypertension 34: 762-767.

Colombari DS, Colombari E, Lopes OU And Cravo SL. 2000. Afferent pathways in cardiovascular adjustments induced by volume expansion in anesthetized rats. Am J Physiol Regul Integr Comp Physiol 279: R884R890.

Colombari E, Menani JV, Talman WT and Johnson AK. 1996. Commissural nucleus of the solitary tract lesions reduce food intake and body weight gain in rats. Brain Res 740 (1-2): 102-108.

Colombari e, Sato Ma, Cravo Sl, Bergamaschi CT, CAMpos JR RR AND LOPES OU. 2001. Role of the medulla oblongata in hypertension. Hypertension 38 : $549-554$.

Cottle MA. 1964. Degeneration studies of the primary afferents of ninth and twelfth cranial nerves in cat. J Comp Neurol 122: 329-345.

Cravo SL, Morrison SF and ReIS DJ. 1991. Differentiation of two cardiovascular regions within caudal ventrolateral medulla. Am J Physiol 261(4 Pt 2): R985-994.

Cravo Sl, Rosas DA, Kalassa F, Korim WS, Hinrichs JM, FERreira-Neto ML, Di MônACo LR AND PEDRINo GR. 2006. Os núcleos vasomotores do bulbo e a regulação cardiovascular: novas evidências e novas questões. Medicina Ribeirão Preto 39: 89-100.

CRILl WE AND ReIS DJ. 1980. Distribution of carotid sinus and depressor nerves in the cat brain stem. Fed Proc 39: 2495-2503.

DAhlström A AND FUXE K. 1964. Evidence for the existence of monoamine containing neurons in the central nervous system. I. Demonstration of monoamines in the cell bodies of brainstem nervous. Acta Physiol Scand 62(232): 1-55. 
DAMPNEY RA. 1994. Functional organization of central pathways regulating the cardiovascular system. Physiol Rev 74: $323-364$

DAMPNEy RA, Horiuchi J, TAgawa T, Fontes MA, PotTs PD AND Polson JW. 2003. Medullary and supramedullary mechanisms regulating sympathetic vasomotor tone. Acta Physiol Scand 177: 209-218.

DAY TA AND SIBBALD JR. 1990. Involvement of the A1 cell group in baroreceptor inhibition of neurosecretory vasopressin cells. Neurosci Lett 113: 156-162.

DAY TA, SibBald JR AND SMith DW. 1992. A1 neurons and excitatory amino acid receptors in rat caudal medulla mediate vagal excitation of supraoptic vasopressin cells. Brain Res 594: 244-252.

DitTMaR C. 1873. Ueber die Lage des sogenennten Gefãsscentrums in der Medulla ablongata. Ber Vehr sãchs Gesellsch Wiss Leipzig Math-Phys CI 25: 449-469.

DobA N AND REIS DJ. 1973. Acute fulminating neurogenic hypertension produced by brainstem lesions in the rat. Circ Res 32: 584-593.

EDERy H AND GUeRTZENSTEIN PG. 1974. A central vasodepressor effect of dyflos. Brit J Pharmac 50: 481-487.

ERnSBerger P, MEeley MP, MANN JJ AND REIS DJ. 1987. Clonidine binds to imidazole binding sites as well as a2-adrenoceptors in the ventrolateral medulla. Eur J Pharmacol 134: 1-13.

FELDBERG WS. 1982. Fifty years on: looking back on some developments in Neurohumoral Physiology. The Sherrington Lectures XVI. Liverpool University Press, Liverpool.

FeldBerg W And Guertzenstein PG. 1972. A vasodepressor effect of pentobarbitone sodium when acting from the liquor space. J Physiol 222: 150-151.

FeldBerg W ANd Guertzenstein PG. 1976. Vasodepressor effects obtained by drugs acting on the ventral surface of the brain stem. J Physiol 258: 337-355.

Feldberg W and Guertzenstein PG. 1986. Blood pressure effects of leptazol applied to the ventral surface of the brain stem of cats. J Physiol 372: 445-456.

FERGUSON AV, WASHBURN DL AND LATCHFORD KJ. 2001. Hormonal and neurotransmitter roles for angioten$\sin$ in the regulation of central autonomic function. Exp Biol Med 226: 85-96.

FINK GD. 1997. Long-term sympatho-excitatory effect of angiotensin II: a mechanism of spontaneous and renovascular hypertension. Clin Exp Phamacol Physiol 24: 91-95.
Fink GD, Bruner CA And Mangiapane ML. 1987. Area postrema is critical for angiotensin-induced hypertension in rats. Hypertension 9: 355-361.

FINLEY JCW AND KATZ DM. 1992. The central organization of carotid afferent projections to the brainstem of the rat. Brain Res 572: 108-116.

Gordon FJ AND MCCANN LA. 1988. Pressor responses evoked by microinjections of L-glutamate into the caudal ventrolateral medulla of the rat. Brain Res 457: 251-258.

Granata AR, Numao Y, Kumada M And Reis DJ. 1986. A1 noradrenergic neurons tonically inhibit sympathoexcitatory neurons of $\mathrm{C} 1$ area in rat brainstem. Brain Res 377(1, 2): 127-146.

GUERTZENSTEIN PG. 1971. Stimulation by nicotine of a vasodilator area on the floor of the fourth ventricle. J Physiol 214: 5-6.

GUERTZENSTEIN PG. 1972. Vasodepressor and pressor responses to drugs topically applied to the ventral surface of the brain stem. J Physiol 224: 84-85.

GUERTZENSTEIN PG. 1973. Blood pressure effects obtained by drugs applied to the ventral surface of the brain stem. J Physiol 229: 395-408.

Guertzenstein PG And Lopes OU. 1980. A depressor area on the ventral surface of medulla. J Physiol 301: $35-36$.

Guertzenstein PG And Lopes OU. 1984. Cardiovascular responses evoked from the nicotine-sensitive area on the ventral surface of the medulla oblongata in the cat. J Physiol 347: 345-360.

Guertzenstein PG AND Silver A. 1973. Further studies on the role of a bilateral chemosensitive zone on the ventral surface of the brain stem in the maintenance of arterial blood pressure. J Physiol 233: 27-28.

Guertzenstein PG AND Silver A. 1974. Fall in blood pressure produced from discrete regions of the ventral surface of the medulla by glycine and lesions. J Physiol 242: 489-503.

Guyenet PG, Filtz TM And Donaldson SR. 1987. Role of excitatory amino acids in rat vagal and sympathetic baroreflexes. Brain Res 407: 272-284.

HaYes K AND WeAVER LC. 1992. Tonic sympathetic excitation and vasomotor control from pontine reticular neurons. Am J Physiol 263(5 Pt 2): H1567-1575.

Head GA, QuaIL AW and WoOdS RL. 1987. Lesions of A1 noradrenergic cells affect AVP release and heart rate during hemorrhage. Am J Physiol Heart Circ Physiol 253: H1012-H1017. 
Hochstenbach SL And Ciriello J. 1995. Plasma Hypernatremia Induces C-Fos Activity in Medullary Catecholaminergic Neurons Brain Res 674: 46-54.

Howe BM, Bruno SB, Higgs KA, Stigers RL AND Cunningham JT. 2004. FosB expression in the central nervous system following isotonic volume expansion in unanesthetized rats. Exp Neurol 187: 190-198.

ITO S AND SVED AF. 1996. Blockade of angiotensin receptors in rat rostral ventrolateral medulla severely reduces sympathetic vasomotor tone. Am J Physiol Reg Integr Comp Physiol 270: R1317-1323.

ITO S AND SVED SF. 1997. Tonic glutamate-mediated control of rostral ventrolateral medulla and sympathetic vasomotor tone. Am J Physiol 273(42): R487-R494.

Ito S, Komatsu K, Tsukamoto K And Sved AF. 2000. Excitatory amino acids in the rostral ventrolateral medulla support blood pressure in spontaneously rats. Hypertension 35: 413-417.

Ito S, Komatsu K, Tsukamoto K And Sved AF. 2001. Tonic excitatory input to the rostral ventrolateral medulla in Dahl salt-sensitive rats. Hypertension 37(2 Part 2): 687-691.

Jeske I, Morrison SF, Cravo SL AND ReIS DJ. 1993. Identification of baroreceptor reflex interneurons in the caudal ventrolateral medulla. Am J Physiol Regul Integr Comp Physiol 264: R169-R178.

JOY MD AND LOWE RD. 1970. Evidence that the area postrema mediates the central cardiovascular response to angiotensin II. Nature 228: 1303-1304.

Katahira K, Mikami A and Otsuka A. 1994. Differential control of vascular tone and heart rate by different amino acid neuro-transmitters in the rostral ventrolateral medulla of the rat. Clin Exp Phamacol Physiol 21: 545556.

Koshiya N AND GUYENET PG. 1996. NTS neurons with carotid chemoreceptor inputs arborize in the rostral ventrolateral medulla. Am J Physiol 270(39): R1273-R1278.

Koshiya N, Huangfu D And Guyenet PG. 1993. Ventrolateral medulla and sympathetic chemoreflex in the rat. Brain Res 609: 174-184.

Li YW, GIeroba ZJ AND Blessing WW. 1992. Chemoreceptor and baroreceptor responses of A1 area neurons projecting to supraoptic nucleus. Am J Physiol 263(32): R310-R317.

Lipski J, KANJHAN R, KRUSZEWSKa B AND Rong W. 1996. Properties of presympathetic neurons in the rostral ventrolateral medulla in the rat: an intracellular study in vivo. J Physiol 490: 729-744.
MiURA M AND ReIS DJ. 1969. Termination and secondary projections of carotid sinus nerve in the cat brainstem. Am J Physiol 217: 142-153.

MiURA M AND REIS DJ. 1972. The role of solitary and paramedium reticular nuclei in mediating cardiovascular reflex responses from carotid baro- and chemoreceptors. J Physiol 223: 525-548.

Moreira TS, Sato MA, Takakura AC, Menani JV AND COLOMBARI E. 2005. Role of pressor mechanisms from the NTS and CVLM in control of arterial pressure. Am J Physiol Regul Integr Comp Physiol 289(5): R14161425. Epub Jul 28.

Moriguchi A, Mikami H, Otsuka A, KatAhira K AND OGIHARA T. 1994. Amino acids in the medulla oblongata contribute to baroreflex modulation by angiotensin II. Brain Res Bull 36: 85-89.

Morimoto S ET AL. 1999. Pressor response to compression of the ventrolateral medulla mediated by glutamate receptors. Hypertension 33: 1207-1213.

Morrison SF, Milner TA And Reis DJ. 1988. Reticulospinal vasomotor neurons of the rat rostral ventrolateral medulla: relationship to sympathetic nerve activity and the $\mathrm{C} 1$ adrenergic cell group. J Neurosci 8: 1286-1301.

Orer HS, Gebber GL, Phillips SW And Barman SM. 2004. Role of the medullary lateral tegmental field in reflex-mediated sympathoexcitation in cats. Am J Physiol Regul Integr Comp Physiol 286: R451-464.

OWSJANNIKOW P. 1871. Die tonischen und reflectorischen Centren der Gefãssnerven. Ber d Akad Wiss Leipzig Math-Phys C123: 135-147.

Paton JF AND Kasparovo S. 1999. Differential effects of angiotensin II on cardiorespiratory reflexes mediated by nucleus tractus solitarii - a microinjection study in the rat. J Physiol 521: 213-225.

PATON JF, Boscan P, Murphy D AND Kasparov S. 2001. Unravelling mechanisms of action of angiotensin II on cardiorespiratory function using in vivo gene transfer. Acta Physiol Scand 173: 127-137.

PEDRINO GR AND CRAVo SL. 2006. Blockade of alpha 1 -adrenoceptors in the median preoptic (MePO) nucleus impairs cardiovascular responses induced by intravenous hypertonic saline (HS) infusion. FASEB J1 20: A360A360.

Pedrino GR, Sera CTN, Cravo SL and Colombari DS. 2005. Anteroventral third ventricle lesions impair cardiovascular responses to intravenous hypertonic saline infusion. Auton Neurosci 117: 9-16. 
Pedrino GR, Maurino I, Colombari DS and Cravo SL. 2006. Role of catecholaminergic neurones of the caudal ventrolateral medulla in cardiovascular responses induced by acute changes in circulating volume in rats. Exp Physiol 91: 995-1005.

Pedrino GR, Rosa DA, Korin WS ANd Cravo SL. 2008. Renal sympathoinhibition induced by hypernatremia: Involvement of A1 noradrenergic neurons. Auton Neurosci 142: 55-63.

Possas OS, CAmpos JR RR, CRAVo SL, LOPES OU AND GuertZensteIn PG. 1994. A fall in arterial blood pressure produced by inhibition of the caudalmost ventrolateral medulla: the caudal pressor area. J Auton Nerv Sys 49: $235-245$.

Ross CA, Ruggiero DA, PARK DH, Joh TH, Sved AF, FERNANDEZ-PARDAL J, SAAVEDRA JM AND REIS DJ. 1984. Tonic vasomotor control by the rostral ventrolateral medulla: effect of electrical or chemical stimulation of the area containing $\mathrm{C} 1$ adrenaline neurons on arterial pressure, heart rate, and plasma catecholamines and vasopressin. $\mathrm{J}$ Neurosci 4: 474-494.

Ross CA, RugGiero DA AND REIS DJ. 1985. Projections from the nucleus tractus solitarii to the rostral ventrolateral medulla. J Comp Neurol 242: 511-534.

Ruggiero DA, Cravo SL, Golanov E, Gomez R, ANWAR M AND REIS DJ. 1994. Adrenergic and nonadrenergic projections of a cardiovascular-active pressor area of medulla oblongata: quantitative topographic analysis. Brain Res 663: 107-120.

SAKAI S AND DAMPNEY RAL. 1990. Tonic cardiovascular effects of angiotensin II in the ventrolateral medulla. Hypertension 15: 274-283.

SAPER CB, REIS DJ AND JOH T. 1983. Medullary catecholamine inputs to the anteroventral third ventricular cardiovascular regulatory region in the rat. Neurosci Lett 42: 285-291.

Sato MA, Menani JV, Lopes ou and Colombari E. 1999. Commissural NTS lesions and cardiovascular responses in aortic baroreceptor-denervated rats. Hypertension 34: 739-743.

Sato MA, Menani JV, Lopes OU and Colombari E. 2001. Lesions of the commissural nucleus of the solitary tract reduce arterial pressure in spontaneously hypertensive rats. Hypertension 38: 560-564.

SATO MA, COlOMbari E AND MORRISON SF. 2002. Inhibition of neurons in commissural nucleus of solitary tract reduces sympathetic nerve activity in SHR. Am J Physiol 282: H1679-H1684.
Smith DW, SibBald JR, Khanna ANd DAY TA. 1995. Rat vasopressin cell responses to simulated hemorrhage: stimulus-dependent role for A1 noradrenergic neurons. Am J Physiol Regul Integr Comp Physiol 268: R1336R1342.

SPYER K. 1981. Neural organization and control of the baroreceptor reflex. Rev Physiol Biochem Pharmacol 88: 24124.

Sun MK AND GUYenet PG. 1986. Hypothalamic glutamatergic input to medullary sympathoexcitatory neurons in rats. Am J Physiol 251(4 Pt 2): R798-810.

TANAKA J, HAYASHI Y, WATAI T, FUKAMI Y, JOHKOH R AND SHIMAMUNE S. 1997. A1 noradrenergic modulation of AV3V inputs to PVN neurosecretory cells. Neuroreport 8: 3147-3150.

Tucker DC, SAPer CB, Ruggiero DA AND Reis DJ. 1987. Organization of central adrenergic pathways: I. Relationships of ventrolateral medullary projections to the hypothalamus and spinal cord. J Comp Neurol 259: 591-603.

URBANSKI RW AND SAPRU HN. 1988a. Evidence for a sympathoexcitatory pathway from the nucleus tractus solitarii to the ventrolateral medullary pressor area. J Auton Nerv Syst 23: 161-174.

URbanski RW AND SAPRU HN. 1988b. Putative neurotransmitters involved in medullary cardiovascular regulation. J Auton Nerv Syst 25: 181-193.

VAN HM, Schiffrin EL, MANN JFE, POSNER BI AND BOUCHER R. 1980. Radioautographic localization of specific binding sites for blood borne angiotensin II in rat brain. Brain Res 186: 480-485.

Willete RN, BARCAS PP, KRIEGER AJ AND SAPRU HN. 1984a. Endogenous GABAergic mechanisms in the medulla and the regulation of blood pressure. J Pharmacol Exper Therap 230: 34-39.

Willete RN, Punnen S, Krieger AJ And SAPru HN. 1984b. Interdependence of rostral and caudal ventrolateral medullary areas in the control of blood pressure. Brain Res 321: 169-174.

Willette RN, Punnen-Grandy S, Krieger AJ And SAPRU HN. 1987. Differential regulation of regional vascular resistance by the rostral and caudal ventrolateral medulla in the rat. J Auton Nerv Syst 18: 143-151. 